\title{
INTELLIGENT AQUAPONICS USING IoT
}

\author{
Sujatha Anand $^{1 *}$, Stephena.E $^{2}$, Indhumathi.G ${ }^{3}$, G.Ancy $^{4}$, D.Madhumitha $^{5}$, S.Swathi $^{6}$ \\ $1,2,3,4,5,6$ \\ Department of Electronics and Communication, Loyola Institute of Technology, \\ Chennai, India \\ Email: 1* sujja13@gmail.com
}

\begin{abstract}
Abstract-Conventional agriculture and aquaculture present the unwelcome situation of great extents of consumption in both land and water resources. The threat of pollution of water bodies also need to be taken into account. The urbanization policies and population explosion with rapid migration from rural areas makes the concept of aquaponics reuse of ecological crop rising and reusing methods essential. This technology coalesces recirculation of water used in aquaculture and hydroponics for crop supplement and water recycle; reduction of pollution and enhancement of efficiency and yield. Hydroponics and aquaculture is proposed in this paper on a combinatory solution for better agriculture practice. Intelligent monitoring of water quality and nutrient circulation can be abstracted, tabulated and summarized. This paper popularizes the implementation of IoT in aquaponics.
\end{abstract}

Keywords —: Arduino, Farm, Plant, Aquaponic, Application, Technology, IoT, Internet, Wi-fi.

\section{INTRODUCTION}

With the rapid development of mobile Internet, Internet of Things (IoT), and wearable devices, the agricultural monitoring has shown an intelligent trend in recent years. The total amount of quality and quantity of agriculture and fish breeding can be improved using aquaponics. The name aquaponics came from aquaculture (fish farming) and hydroponics (soilless plant production). Also, an effective yielding ${ }^{[1]}$ can be produced using aquaponics system. This method is simple, relatively cheap, and a great introduction to aquaponics growing. Aquaponics is a great option for anyone wanting to try a different angle as a stayat-home gardening, as it has a certain 'life' factor missing from traditional stay-at- home gardening. Soil less agricultural techniques are implemented in aquaponics. Instead it uses dissolved nutrients and water circulation like traditional hydroponics. In aquaponics, fish waste by products produce nutrients and this can be used rather than the inorganic soluble nutrient salts like pesticides and fertilizers used in traditional hydroponics ${ }^{[2]}$ Water-based system is the basic principle in which fish waste provides nutrition for plants, and plants filter and oxygenate the water in turn. The breakdown of fish waste into nutrients is done by an integral component called bacteria and the plants can absorb this as a nutrient. Aquaponics, which is naturally organic, water efficient, space efficient, and produces prolific amounts of plant growth $^{[3]}$ Consumption of large amount 
of fishes is done in a large enough system. Space efficiency is usually a concern with growing as a step- athome $^{[4]}$, and aquaponics is able to be scaled up or down to almost any scenario. It is one of the most productive growing methods known to man. An aquaponics system should maintain a neutral $\mathrm{pH}$ of 7.0, and it is the valid $\mathrm{PH}$ rate ${ }^{[5]}$. Potassium and calcium are typically added in the forms of the bases potassium hydroxide $[\mathrm{KOH}]$ and calcium hydroxide [Ca $(\mathrm{OH}) 2]$, and iron is added in the FeDTPA form and is highly soluble. The plants should available under a $\mathrm{pH}$. of neutral7.0.

\section{APPLICATION SCENARIOS}

Various sensors used here are temperature sensor, turbidity sensor, $\mathrm{pH}$ sensor, chemical sensors to determine the temperature, salinity, $\mathrm{pH}$ level and water level. Aquaponics is highly beneficial in farming techniques, environmental, health and nutrition. These applications are mentioned below:

A. Farming Technique:

A recent survey says aquaponics uses $90 \%$ less water than traditional farming and it's a fact too. We can grow this aquaponic on any time, in any weather and anywhere on the planet as it recycles the water also less water conservation. There's no weeding for cultivators and plants grow faster due to the naturally fortified water from the fish. For the commercial farmers, aquaponics produces dual income i.e. from fish and vegetables. The fish waste contains more amount of

Copyright $(\odot$ Author ammonia which reduces the use of fertilizers. Land conservation is also an effective factor

B. Environmental Technique:

Energy Conservation: In aquaponic system there is a less use of energy than conventional commercial farming. All energy used in aquaponics system is electrical. We can also use an alternate energy system such as solar, wind, and hydroelectric power to our farm. This will save high amount of energy and there is no wastage of power.

Water Conservation: Water conservation is one of the most referred technique in agriculture. In aquaponics system, it uses $90 \%$ less water than traditional farming. Moreover, water and nutrients are recycled in a closed-loop fashion. This will conserve more amount of water.

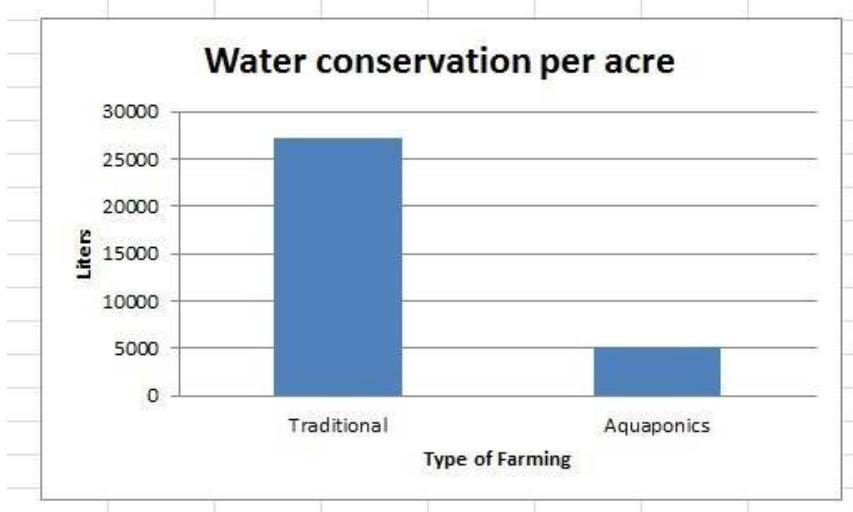

Fig.1. Water conversation per acre

Fig.1. It determines the water conservation per acre for both traditional and aquaponics systems. The above fig shows that, in traditional method water conservation is high but for Aquaponics system water conservation is low.

Land Conservation: Land
vation is highly provided in 
aquaponics system because, it's the combination of hydroponics and aquaculture where both are planted one over another. This will save land, water, money, energy and other valuable resources.

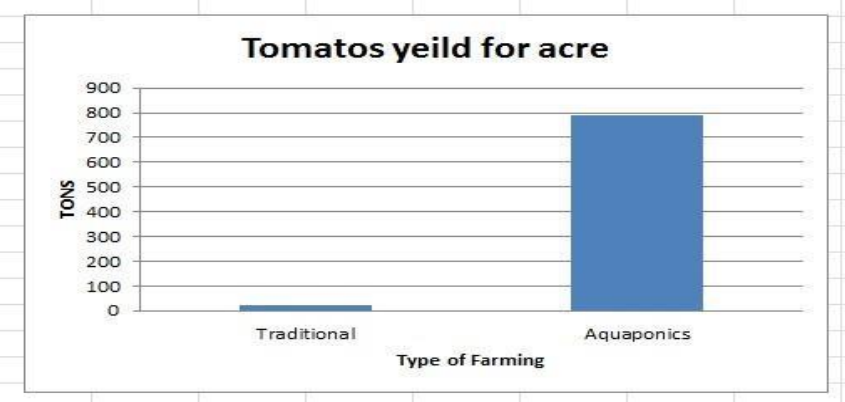

Fig.2.Tomato yield for acre

Fig.2. It determines the tomato yield per acre for both traditional and aquaponics systems. The above fig shows that, in traditional method tomato yield is low but for Aquaponics system tomato yield is high.

\section{Health \& Nutrition:}

The fertilizer used here is from cold blooded fish which do not carry the E. coli or Salmonella, which doesn't cause any harm to humans. Fishes convert the plant protein to animal protein in a faster rate. Fishes do not have growth hormones, mercury and antibiotics. Plants we are growing have no antibiotics. The taste of our products better than other grocery products. Adding natural fertilizer i.e. fish waste doesn't produce any side effects.

\section{METHODOLOGY}

A.Intelligent Aquaponic System:
Aquaponics is a word refers to "combination of hydroponics and aquaculture". Here both fishes and plants grow in a same media where the water is recycled. Intelligent is the word refers to usage of IOT in aquaponics. Therefore, intelligent aquaponics is the concept of bio- integrated farming system combined with internet of things based electric technology.

\section{B.Internet of Things:}

IoT is used to indicate the water quality by graphical user interface (QUI). In aquaponics the IoT collects information from the physical environment and these information's are used in the application layer. The sensor outputs can be monitored using IoT. Healthy environment is maintained by using continuous monitoring of data and making necessary adjustment. Sensor outputs are uploaded to Thing speak and an IoT analytical platform provide real time data visualization and analysis. This aquaponics method requires both $\mathrm{AC}$ and $\mathrm{DC}$ power supply. Here DC supply is used for the

\section{C.System Design}

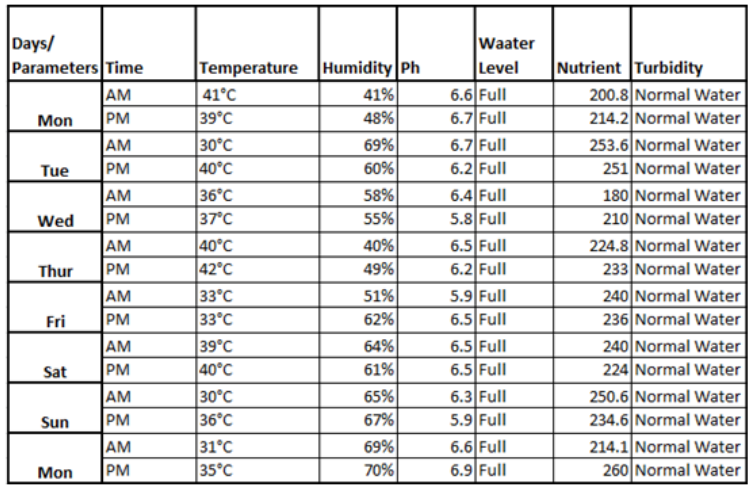

Table 1: Readings measured for temperature,humidity,ph,waterlever, nutrient and turbidity 
The system design consists of various sensors like temperature sensor, turbidity sensor, water level sensors are used to monitor the system continuously. Motor is used to pump the water from fish to plant vice versa. Other equipment's such as filter, relay, power supply, IoT, Arduino UNO are used.

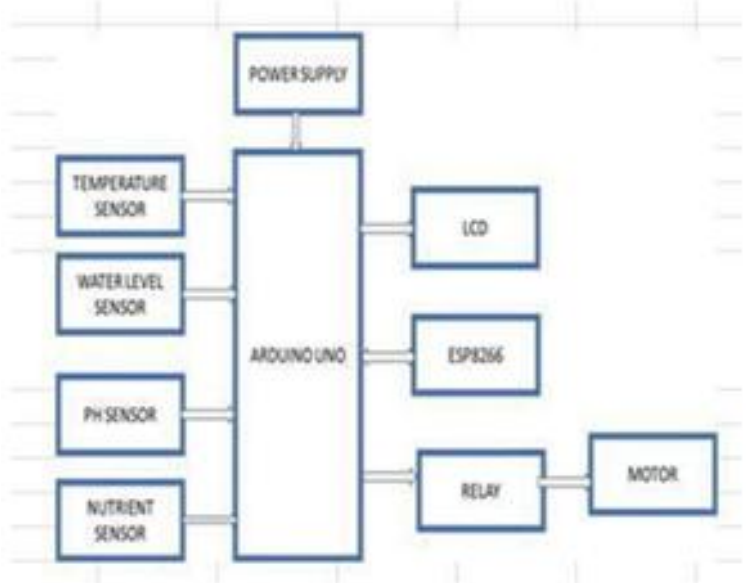

Fig.3. Block Diagram for Aquaponics system

Hardware Implementation

Power Supply

Arduino and the AC supply is for the submersible pump. The total amount of DC supply is $12 \mathrm{~V}$ and $\mathrm{AC}$ is $230 \mathrm{~V}$. The function of power supply is given as: transformation of electric current from source to the voltage, current and frequency to power the load.

\section{Arduino Uno}

Arduino is an open source device used for both hardware and software implementation. It can able to read inputs like sensors and convert into an output for turning on motor, LED. It contains 14

Copyright $(\odot$ Author pins and out of it 6 pins are analog. It operates at $5 \mathrm{~V}$ power supply

Temperature Sensor:

Wireless temperature sensors are used $24 / 7$ monitoring of the aquaponic sensor. It also has the ability to track environmental changes and the plants and fishes efficiency can be highly increased.

\section{EXPERIMENTAL SETUP}

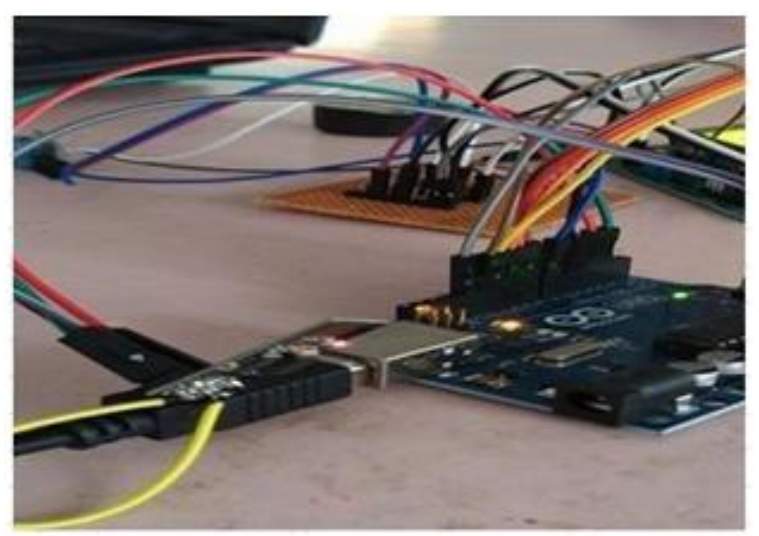

Fig.4.This is the hardware setup of Aquaponics system though which we can get the take readings for temperature level, water level etc...

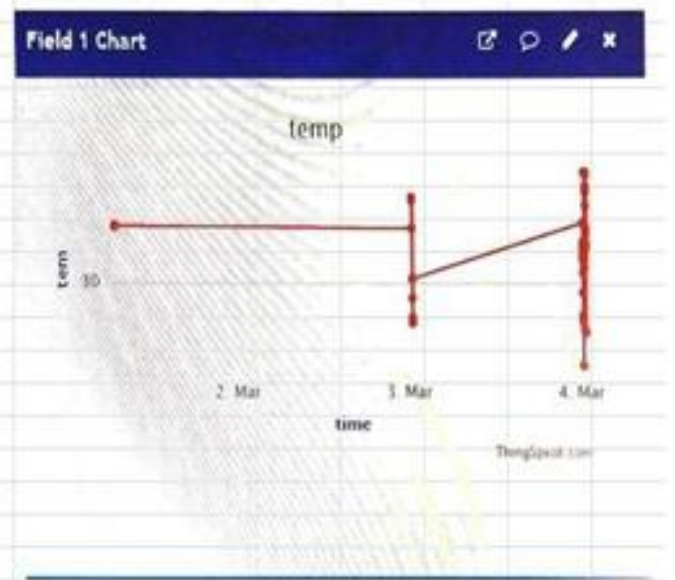

Fig.5.This is the whole setup of Aquaponic system which includes fish tank, hardware connections and plant growth 

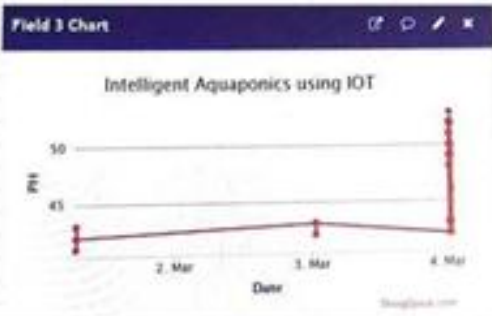

Fig.6.Temperature analysis

The above figure represents the measurement of temperature in the fish tank with respect to time. Temperature sensor is used to monitor the temperature. In this figure the level of the temperature is normal for the growth of both fishes and plants.

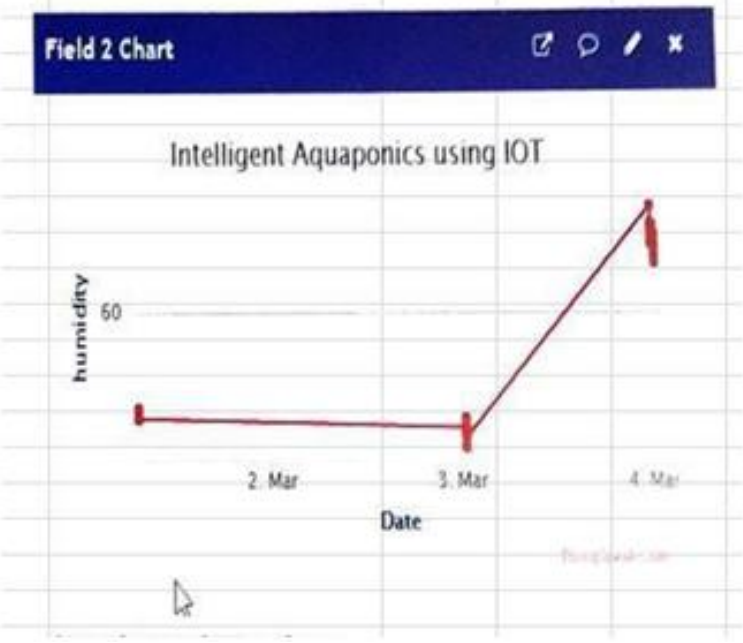

Fig.7.Humidity analysis

The above figure represents the humidity level with respect to time.

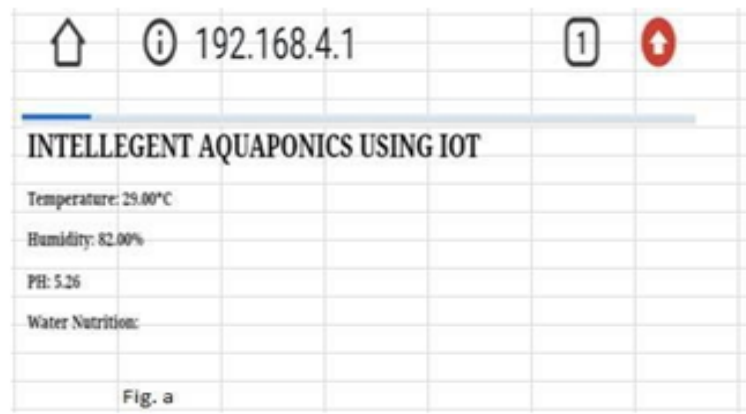

Fig.8.ph analysis

The above figure represents the ph level of the fish tank with respect to time. Here the ph value is normal for the fish tank. If the value exceeds above 7 the fishes will not exists.

\section{RESULTS AND DISCUSSION}

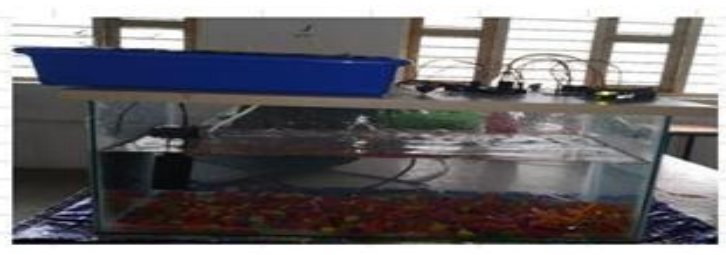

Fig.9. Reading Taken in the morning

Readings are taken in the morning and afternoon as it varies for each time. (Fig.9) shows the reading taken in the morning for temperature, humidity, ph and water level. (Fig.10)reading taken in the afternoon. Here the ph value varies from morning reading.

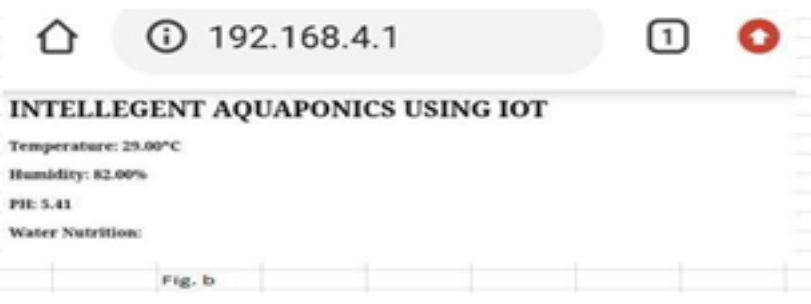

Fig.10. Reading Taken in the Afternoon 
From the above Fig (9) and Fig(10) we infer that the parameters like temperature ,humidity, ph and water level were considered the results shows that the temperature is at $29^{\circ} \mathrm{c}$ and humidity is at $82 \%$ which remains the same at morning and afternoon by the above value it is evident that the system is efficient because the ph value is less than 7 , hence it does not harm the fishes that is present in the aquaphonics system

\section{CONCLUSION}

This method is used to automate real-time data collection and analysis like the conditions of fish and plants at different weather can be continuously monitored and analyzed. It will automatically correct the measures to balance the deviation. This will highly increase the expense and reduce the human works. Various parameters like Temperature, $\mathrm{pH}, \mathrm{O} 2$ content etc. can be viewed in real time and the data's will be collected from system. The operator is connected to the operations cloud. This can control the various features of the aquaponics system such as heaters, lights and fish feeders. All the data's collected can be analysed to get an insight into the growth as well as the energy/systems utilizations. This can be used to make the models for Predictive analytics robust.

\section{REFERENCE}

[1] Yaoguang wei,Wenshu Li,Dong an,Daoliang Li, "Equipment and intelligent Control system in aquaphonics: A Review",IEEE Access, 2018

[2] David C.Love,Jillian P .Fry, Laura Genello, "An International survey of Aquaponics Practitioners", PLOS ONE,July 2014.
[3] Deepa Chakravartty,Asish Mondal,Propa, " Role of aquaponics in the sustenance of coastal IndiaAquaponics is a solution for modern agriculture in ecologically sessitive Indian Mangroove sunderbans:A review" International Journal of fisheres and Aquatic studies,Feb 2017.

[4] Reshmi Menon and Shahana G.V and Sruthi V, Small Scale Aquaponics System, International Journal of Agriculture and Food Science Technology, 2013, 4 (10), 970-980.

[5] J Guerrero, Carrollton F Edwards, DY Wan and V Sheth, Using Wireless Sensor Network Controls to Monitor an Indoor Aquaponics System, RET: Research Experiences for Teachers on Sensor Networks, 2013.

[6] D Wang, J Zhao, L Huang and D $\mathrm{Xu}$, Design of a Smart Monitoring and Control System for Aquaponics Based on Openwrt, 5th International Conference on Information Engineering for Mechanics and Materials, 2015

[7] da Silva Cerozi B, Fitzsimmons K. Effect of dietary phytase on phosphorus use efficiency and dynamics in aquaponics. Aquaculture International 2017; 25(3):1227-1238

[8] R. Gómez-Chabla, K. Real-Avilés, K. Calle, C. Morán, F. Gavilánez, D. Arcos- Jácome, and C. Chávez, “A monitoring system for lettuce cultivation in an NFT hydroponic system A case study," in Proc. 2nd Int. Conf. ICTs Agronomy Environ. Cham, Switzerland: Springer Jan. 2019. 